\title{
REDE WEB DE MUSEUS: Relato de experiência na gestão e acesso aos acervos culturais do Estado do Rio de Janeiro
}

\author{
RED WEB DE MUSEOS: Relato de experiencia en la gestión y acceso a \\ los acervos culturales del Estado de Río de Janeiro
}

\section{MUSEUM WEB NETWORK: Report of experience in management and access to the cultural collections of the State of Rio de Janeiro}

\author{
Elenora Nobre Machado' \\ Ericka Madeira de Souza"
}

Palavras-chave:

Rede Web de Museus

Base de dados

museológica

Gestão de acervos

museológicos

Objetos digitais

Reuso

\section{Resumo:}

Relata experiência no processo de criação de política pública de gestão, acesso e disponibilização dos acervos dos museus vinculados à Secretaria de Estado de Cultura do Rio de Janeiro e outros equipamentos culturais sediados no Rio de Janeiro, através de projetos específicos, e a importância das novas tecnologias da informação no aprimoramento da documentação museológica. A Rede Web de Museus é apresentada como política que visa ampliar o acesso aos acervos,oferecendo orientação técnica e ferramentas para a produção de acervos digitais e seu reuso, promovendo a articulação em rede. As formas de adesão à Rede e aplataforma tecnológica da Rede - um sistema de base de dados web compartilhado, voltado para a disponibilização e gestão de acervos museológicos - o SISGAM, são apresentadas.Futuros desdobramentos para a atualização da Rede Web de Museus e sua plataforma tecnológica, são relatados. 


\begin{abstract}
Resumen:
En el caso de los museos de la ciudad de Río de Janeiro y otros equipos culturales que se funden en Río de Janeiro a través de proyectos específicos y la importancia de las nuevas empresas, tecnologías de la información en el perfeccionamiento de la documentación museológica. La Red Web de Museos es presentada como política que busca ampliar el acceso a los acervos, ofreciendo orientación técnica y herramientas para la producción de acervos digitales y su reuso, promoviendo la articulación en red, las formas de adhesión a la Red se describen. La plataforma tecnológica de la Red - un sistema de base de datos web compartido, orientado a la disponibilidad de y gestión de acervos museológicos - el SISGAM, es presentado. Se reportan futuros desdoblamientos previstos para la actualización de la Red Web de Museos y su plataforma tecnológica.
\end{abstract}

\section{Palabras clave:}

Red Web de Museos

Base de datos museológica

Gestión de acervos museológicos

Objetos digitales

Reuso

\section{Keywords:}

Museum Web Network

Museum database

Museological collections management

Digital objects

Reuse

\section{Abstract:}

It reports on experience in the process of creating a public policy for managing, accessing and making available the collections of museums linked to the State Secretariat of Culture of Rio de Janeiro and other cultural facilities based in Rio de Janeiro through specific projects and the importance of new technologies in the improvement of museum documentation. The Museum Web Network is presented as a policy that aims to expand access to the collections, offering technical guidance and tools for the production of digital collections and their reuse, promoting network articulation, the ways of joining the Network are described. The Network's technological platform - a shared web database system, dedicated to the provision and management of museum collections SISGAM, is presented. It is reported future developments planned for the updating of the Museum Web Network and its technological platform. 


\section{REDE WEB DE MUSEUS: Relato de experiência na gestão e acesso aos acervos culturais do Estado do Rio de Janeiro}

\section{Introdução}

O presente artigo é um relato sobre a nossa experiência no processo de criação da Rede Web de Museus, na tentativa de desenvolver uma política pública para os acervos digitais culturais do estado do Rio de Janeiro, oferecendo facilidades e ferramentas que possibilitem a disponibilização e o acesso a estes acervos e uma maior integração e troca de experiências entre as instituições.

Iniciamos este processo com a digitalização dos acervos dos museus vinculados à Fundação Anita Mantuano de Artes do Estado do Rio de Janeiro (FUNARJ) e à Secretaria de Cultura do Estado Rio de Janeiro (SEC/RJ), no final dos anos 80, quando os dez museus vinculados à FUNARJ e à SEC/RJ trabalhavam com sistemas locais utilizando o mesmo software.

Posteriormente, em 2007, com o Projeto Rede de Museus, o maior desafio foi planejar uma nova forma de gerenciar as coleções dos museus da FUNARJ, através da constituição de uma base de dados colaborativa, acessada por um navegador web, que interligasse os nossos museus, facilitando a comunicação e promovendo maior segurança para os acervos. Este projeto permitiu ainda a ligação destes museus em rede através da utilização de um sistema comum, o Sistema de Gerenciamento de Acervos Museológicos (SISGAM), desenvolvido durante o projeto.

Em 2013, através do projeto Rede Web de Museus do Estado do Rio de Janeiro, foi ofertada, gratuitamente, a outros museus e centros culturais, sediados dentro do território do estado do Rio de Janeiro, a possibilidade de utilizarem o SISGAM em suas metodologias de trabalho, facilitando a catalogação edinamizando o gerenciamento de seus acervos, promovendo a interligação com outras instituições culturais e a disponibilização de suas coleções na web.

Este artigo está estruturado da seguinte forma: Introdução, com um panorama geral sobre o assunto abordado; os itens 2 e 3 ressaltam as facilidades alcançadas com os museus na web, conceituando objeto digital, curadoria, preservação e reuso; o item 4 relata o início da informatização dos acervos da FUNARJ/SEC-RJ; nos itens 5 e 6 discutimos a importância do Projeto Rede de Museus e a criação do Sistema de Gerenciamento Museológico (SISGAM) para a divulgação de acervos museológicos estaduais; e no item 7 , é apresentado um panorama atual da Rede Web de Museus, os benefícios que proporciona para as instituições participantes e suas perspectivas e desdobramentos futuros, visando dar continuidade à política estadual de acervos digitais culturais que vem sendo delineada pela Superintendência de Museus da SEC/RJ.

\section{Museus na web: visibilidade, acesso e uso}

Em um ambiente digital, eficácia e eficiência nos serviços de informação estão cada vez mais sendo exigidas pelos usuários, fazendo com que os sistemas de indexação e de recuperação da informação estejam cada vez mais sofisticados.

A partir da década de 1980, delineou-se um espaço aberto de grande fluxo de comunicação por meio da interconexão mundial de computadores e suas memórias, a este espaço chamou-se ciberespaço (LÉVY, 2009, p.76-82). Este novo 
ambiente trouxe consigo um novo meio também de ações culturais, o que fez com que as instituições deste perfil se adaptassem a esta realidade, gerando reflexões sobre as suas funções sociais e o reflexo de suas relações com a sociedade contemporânea.

Com relação aos museus, em 1986, Varine (2009), teórico renomado na área cultural e personalidade expressiva do ICOM"I', do qual foi diretor de 1965 a 1974, dissertou sobre a transformação social e cultural que estas instituições testemunham perante a humanidade e alerta para a necessidade destes equipamentos reverem suas funções sociais e educativas em função de um novo perfil da sociedade frente aos moldes que surgiram através da nova influência das tecnologias. Chamou atenção para a recolocação dos museus nesse novo contexto e o desafio que figurava, enquanto aparato de desenvolvimento social, em apoio a esta era digital que vivenciamos desde então.

A partir da década de 1990, os museus começaram a desbravar este novo espaço, explorando novos níveis de relação e interação entre suas obras e os seus públicos. A ocupação deste território intangível e recente, mas de muitas possibilidades, logo permitiu perceber o alcance da projeção de comunicação e da capacidade de ampliação dos potenciais de difusão e acesso às suas coleções.

No final da década de 1990, a museóloga Tereza Scheiner (2009, p. 50-57) reforça a vertente de que o museu, na medida em que mantém, preserva e expõe objetos representativos da sociedade ou de um grupo social, torna-se um reflexo desta parcela de indivíduos. Ele orienta seus discursos conforme as memórias materializadas naqueles objetos que comunicam a história, criando a partir de suas exposições uma realidade simbólica da qual os objetos expostos são testemunhos.
Assim como as informações sobre as coleções de museus, o grande volume de informações que veicula no ciberespaço também necessita de uma organização capaz de permitir uma rápida recuperação desses recursos. O tratamento técnico dado aos documentos com as novas tecnologias de informação e comunicação, que procuraram facilitar a organização e o processamento dessa grande quantidade de informações, contribuiu para promover a integração de diferentes instituições, produtoras e disseminadoras de informação, que até então funcionavam de maneira estanque.

Neste contexto, os museus, enquanto centros de produção e difusão de informações, começaram a buscar uma nova forma de interação entre os seus acervos e seus públicos, com o objetivo de disseminar de forma mais ampla os conteúdos informacionais provenientes das pesquisas realizadas em suas coleções.

Ao lado dos recursos cada vez mais avançados da web, as novas tecnologias ampliaram as possibilidades de comunicação dos museus proporcionando novos meios de divulgação e apresentação de seus acervos, permitindo maior integração entre o usuário e a instituição através de diversas atividades virtuais, utilizando materiais oriundos de suas coleções, e na área de pesquisa e documentação, através do acesso à base de dados museológicos.

Os museus deixaram de existir apenas em seus espaços físicos e passaram a fazer parte do mundo digital, podendo ser acessados e virtualmente visitados por um número muito maior de pessoas.

Começaram a experimentar novas formas de envolvimento com os seus usuários, que também passaram a ser criadores de conteúdos e colaboradores no processo de divulgação destas instituições, 
através das redes sociais, que permitem que estas instituições compartilhem conteúdos em rede e em modo virtual fazendo uso de ferramentas como Blogs, Twitter, Facebook, Instagram, dentre outras, facilitando o processo de comunicação com o seu público. Plataformas como sites institucionais, bases de dados, publicações digitais, veiculam e permitem que informações de interesse comum ao redor do mundo sejam compartilhadas e acessadas a partir de qualquer localidade, através de dispositivos móveis, como laptops, smartphones e tablets.

As relações em rede também representam a sociedade contemporânea e auxiliam na compreensão das transformações culturais, pois a rede é um

elemento estruturante e dinamizador da circulação de fluxos comunicacionais e informacionais que acaba por atingir praticamente todas as áreas da sociedade e influencia suas práticas e modos de funcionamento (MARTINS; SILVA; CARMO, 2018, p. 195).

Em paralelo ao potencial que 0 ambiente digital promove nos dias atuais, foi imprescindível que os museus desenvolvessem projetos compatíveis com os avanços nas áreas de organização e gerenciamento de informações.

A presença de sistemas de informação digitais e bases de dados específicas no gerenciamento das coleções museológicas deu início a um novo "fazer museológico" na área de comunicação, documentação e catalogação de acervos. A fim de construir um padrão de nomenclaturas e termos descritivos dos objetos museológicos e para a consolidação de um bom sistema de recuperação de informação, foi necessária a utilização de vocabulários controlados, ontologias, construção de padrões de metadados e novas práticas de curadoria digital.

\section{Objetos digitais: curadoria, preservação e reuso}

A seguir faremos algumas considerações a respeito de objetos digitais para melhor entendimento da nossa proposta de trabalho.

Objetos digitais são produzidos diariamente por grande parte da população mundial e, principalmente, por centros de informação e pesquisa, como museus. Eles podem ser criados já em meio digital ou transformados do meio analógico para o virtual, através da digitalização.

Dois dos componentes essenciais para a apresentação de qualquer objeto digital são: os hardwares, componentes físicos do notebook ou de outros dispositivos eletrônicos, como teclado, mouse; e os softwares, estrutura lógica e funcional destes equipamentos, o programa ou o conjunto de programas que articulam as funções e possibilidades dos computadores ou dispositivos, por exemplo, os navegadores web, sistemas operacionais dos aparelhos, programa Excel e outros.

Estes objetos, de acordo com Santos (2014, p. 47), não estão necessariamente registrados ou fixados em uma unidade física, mas em unidades lógicas, suas formas de exibição e formatação apresentadas ao olho nu são variáveis e estão condicionadas aos softwares e hardwares compatíveis com sua composição original.

Conforme a demonstração elaborada por Sayão (figura 1), a ilustração expõe a estrutura lógica do objeto digital, composta apenas por uma combinação numérica binária, cuja leitura e interpretação estão condicionadas ao softwareapropriado que é capaz de decodificar a mensagem contida nos números e apresentá-la em formato de linguagem reconhecida pelo usuário que acessa o documento. 


\section{INTERPRETADOR}

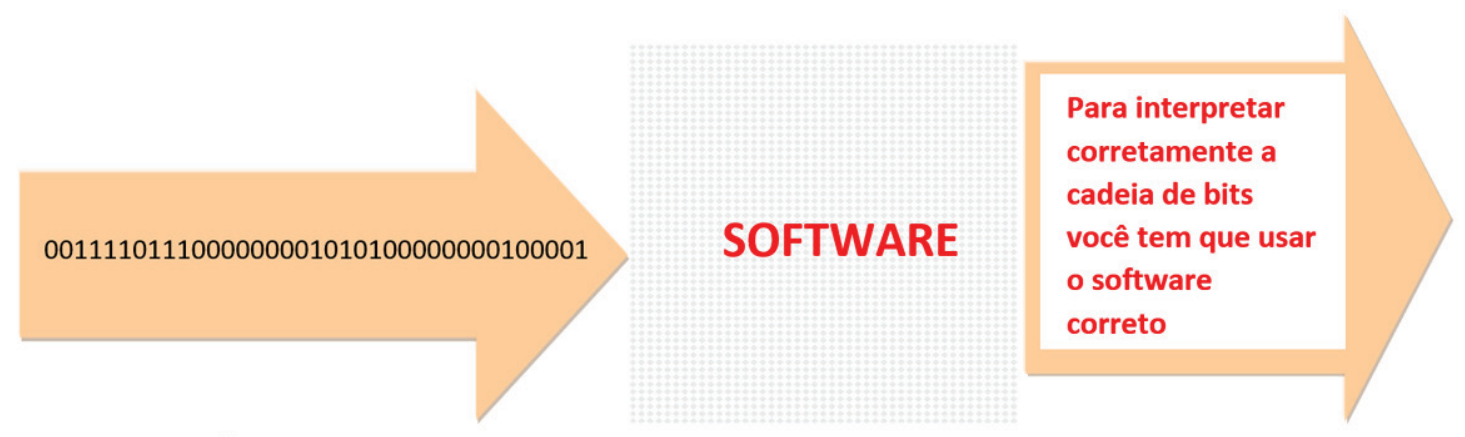

Figura 1 - Interpretação de cadeia de bits Fonte: SAYÃO, 2016a, slide 55

Os objetos digitais são conceituais e "[...] não necessariamente implica na fixação de dados em unidades físicas e sim em unidades lógicas [...]" (SANTOS, 2014, p. 47), devem significar dentro de suas instituições mais do que apenas representações digitais dos acervos físicos, pois suas possibilidades de uso e reuso são extremamente flexíveis, desde que recebam os tratamentos técnicos e gerenciamentos adequados, permitindo essa alta usabilidade.

No caso das coleções digitais, a ideia de preservação está atrelada a outros tipos de demandas de ações em torno destes objetos digitais. As maiores causas de perda informacional são a degradação dos materiais em que estão inscritos e o desaparecimento dos softwares de leitura e decodificação destes objetos. Para manter o acesso contínuo a estes objetos, da maneira como foram projetados, é preciso manter sua estrutura lógica em constante atualização e alteração, como a mudança de formatos, renovação de mídias, hardwares e softwares, ou seja, muitas vezes é preciso intervir nele através da renovação de suas mídias de armazenamento, modificação e atualização do código de linguagem, por exemplo.
A preservação digital é um compilado de "[...] ações requeridas para manter o acesso a materiais digitais além dos limites de falha da mídia ou da mudança

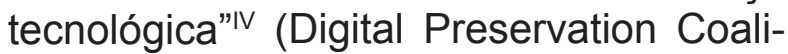
tion - DPC, 2008, p. 24), e é um campo recém explorado pelas equipes técnicas de instituições museológicas. Tal qual a preservação de objetos físicos, exige recursos pouco comuns em instituições culturais de pequeno porte.

Não basta somente a proteção física da mídia que comporta o objeto digital ou dos dispositivos eletrônicos que são capazes de exibi-los. O acesso ao conteúdo não se limita à consulta ao objeto digital, mas sim à capacidade de decodificação por meio dos equipamentos e programas devidos que viabilizam sua compreensão.

Conforme Sayão (2016a), as principais causas que resultam na perda informacional dos objetos digitais são a degradação dos suportes físicos, hardwares, e o desaparecimento dos softwares de leitura e decodificação dos objetos e estes danos são muito comuns em virtude da obsolescência tecnológica.

O grau de usabilidade de um objeto digital refere-se à sua capacidade de ser 
reutilizado em mais de um contexto. O seu reuso proporciona múltiplas facetas de pesquisa a seu respeito, por exemplo, e endossa a história do objeto através do acréscimo de mais informações em sua documentação, contribuindo para o enriquecimento do objeto e dos temas que o mesmo representa, potencializando seu significado cultural.

Uma das grandes contribuições dos acervos digitais culturais é a multiplicidade de acessos e consultas ao item ao mesmo tempo e de diferentes lugares ao redor do mundo. A promoção da socialização e do compartilhamento de dados, de modo que os itens digitais não fiquem restritos às análises de seu contexto original e alcancem novas audiências nestas instituições, movimenta o fluxo de informações através de novos canais de comunicação.

Essa pluralidade de açõesbeneficia e enriquece as coleções físicas dos museus, contribuindo para uma transversalidade e intercâmbio de conhecimento entre as demais instituições, que são referências da guarda e comunicação da memória da sociedade e produtoras de informação.

A verdade é que não há um limite de serviços que possam ser idealizados e realizados com estes materiais. Os objetos digitais podem ser utilizados em tantos serviços quantos forem pensados pela equipe ou demandados pela comunidade usuária da informação.

A curadoria digital torna possível que se atinjam outros objetivos, muito maiores que apenas o acesso aos materiais digitais de uma instituição. É capaz de potencializar a valorização dos bens culturais, no caso dos museus, através da interação destes ativos com outros ativos digitais, em outras conjunturas de pesquisa e análise.

Abbott (2008) afirma que o conceito inclui não só as ações de preservação digital, mas todo o processo de gestão des- tes dados, desde o planejamento de sua criação até as boas práticas de digitalização, vertente também apoiada pelo Digital Curation Centre - DCC ${ }^{\vee}$ (2014a), que sintetiza a curadoria digital na manutenção, preservação e agregação de valor aos documentos digitais e propõe um modelo de ciclo de vida da curadoria digital (DIGITAL CURATION CENTRE- DCC, 2014b).

O reuso fomenta também a interdisciplinaridade de pesquisas a partir do compartilhamento das informações obtidas e geradas e do conhecimento adquirido, "[...] essas tecnologias têm o potencial não somente de engajar novas audiências para as coleções dos museus, mas também de produzir concepções inéditas de produtos e serviços culturais" (SAYÃO, 2016b, p. 8).

\section{Do papel ao computador: um avanço para a recuperação da informação nos museus da SEC/RJ}

O projeto de informatização dos acervos dos museus da FUNARJ e da SEC-RJ iniciou-se no ano de 1990, sob a supervisão da Coordenação de Documentação da Diretoria de Museus (DIM) - atual Superintendência de Museus -, da FUNARJ, que coordenou todas as etapas do projeto.

Gerenciadas pela Diretoria de Museus estavam dez unidades: Museu Histórico do Estado do Rio de Janeiro (MHERJ), Museu de Artes e Tradições Populares (MATP), Museu Antonio Parreiras (MAP), Museu Carmen Miranda (MCM), Museu do I Reinado (MIR), Museu dos Teatros (MT), Museu dos Esportes (ME), Casa de Oliveira Vianna (COV), Casa de Casimiro de Abreu (CCA) e Casa de Euclides da Cunha (CEC).

As dificuldades foram muitas, pois desde 1987 delineava-se o projeto, porém não havia recurso suficiente para executá-lo, até que em 1990, os trabalhos foram iniciados. Foi contratada empresa espe- 
cializada em sistemas de informação para realizar consultoria na área de informatização de acervos, que optou por utilizar um software livre, o CDS/ISIS desenvolvido pela Divisão de Informação e Informática da UNESCO, responsável pela sua manutenção e aprimoramento.

O sistema foi criado para utilização local, com características próprias, para suprir as necessidades de organização, controle, divulgação e segurança dos acervos museológicos e documentais da SEC/RJ. Atendia ao acervo museológico e ao acervo documental. Esse mesmo sistema, específico para acervos bibliográficos, foi instalado nas bibliotecas dos museus.

Foram realizadas várias reuniões técnicas com os museólogos de cada museu para avaliar as suas necessidades de controle e gerenciamento do acervo, e otimização de recuperação da informação. $\mathrm{Na}$ época, já se pensava em uma padronização na entrada dos dados e, por isso, cada museu apresentou um diagnóstico de suas coleções através de um levantamento de tipos de materiais constituintes dos acervos, técnicas e autores visando a construção de listas de termos específicos e um manual de entrada de dados para o sistema.

Todos estes encontros foram realizados em conjunto com a empresa Infosys, através dos consultores Luis Fernando Sayão e Carlos Henrique Marcondes, que customizou o sistema Micro-Isis para atender as necessidades dos museus, e com outros diversos profissionais da área, que contribuíram para o efeito final.Muito se trabalhou até que chegássemos a uma ficha que atendesse às diferentes tipologias de acervos existentes. Chegamos a uma ficha que não foi a ideal, mas que veio ao encontro do que precisávamos. Pretendíamos que todos os museus trabaIhassem com o mesmo software facilitando o gerenciamento das coleções e promovendo maior integração informacional através da unificação dos procedimentos de catalogação e entrada de dados.

Foram adquiridos equipamentos e realizados treinamentos de capacitação para os museólogos trabalharem na nova base de dados, porém os resultados só foram aparecendo a longo prazo.As equipes técnicas treinadas tinham dificuldades em utilizar o computador e confiavam mais nas fichas em papel, que continuavam presentes na metodologia de trabalho, além das dificuldades orçamentárias que eram constantes.

Com a continuidade dos trabalhos e as facilidades de recuperação e geração de relatórios de pesquisa, que o sistema proporcionava, os acervos foram sendo digitalizados. Com o advento de inovações no software e a necessidade de atualização, em 1995, o sistema foi reavaliado e sofreu alterações parciais.

Para a manutenção do padrão das entradas de dados foi elaborado um novo manual para os usuários e para o sistema. Foram atualizadas as tabelas de materiais, técnicas, localização, autor e atividades, entre outras, para controle de vocabulário.

Em 2001, outra atualização se fez necessária e o sistema passou a utilizar o CD/ISIS for Windows - Winisis - versão com interface gráfica para o sistema operacional Windows, quando foram inseridas imagens do acervo na base de dados. Essas imagens não vinham inseridas na ficha do objeto, eram abertas em outra área, e eram nomeadas com o número de Inventário Patrimonial de cada peça. Ainserção das imagens foi muito importante para a segurança e controle do acervo dos museus.

Até 2007, os trabalhos de inserção de dados no sistema continuaram e, devido às dificuldades técnicas e operacionais enfrentadas pelos museus, passaram a ser centralizados na Diretoria de Museus (DIM), 
que montou uma central de catalogação com vários museólogos entrando com os dados enviados pelos museus. Vale ressaltar que, apesar das dificuldades enfrentadas, muitos foram os esforços dos profissionais dos museus e da própria Diretoria de Museus durante todos esses anos, de organizar os serviços técnicos das unidades, estabelecendo normas de trabalho e dotando os museus de condições para o seu bom funcionamento e para a preservação, segurança e divulgação de seus acervos.

Naquela época já era possível se vislumbrar, ainda que de forma inicial, a possibilidade de construção de uma interface colaborativa que integrasse os acervos digitais dos museus vinculados à SEC/FUNARJ, promovendo maior interação entre as instituições museológicas e o acesso à informação em tempo real.

\section{O projeto rede de museus: integração}

Dando continuidade aos esforços no sentido de promover a integração e colaboração entre as suas unidades, e atentos a todo o potencial que a internet podia oferecer em termos de infraestrutura de comunicação e interação, e ainda, pensando em desenvolver conteúdos de qualidade e de alto valor informacional que estivessem disponíveis online,foi criado em 2007, com o apoio financeiro da Oi Futuro, o Projeto Rede de Museus.

O projeto teve como principais propostas: (a) promover a integração de oito unidades museológicas vinculadas à FUNARJ/SEC: Museu de História e Artes do Estado do Rio de Janeiro (MHAERJ), Museu Antonio Parreiras (MAP), Museu Carmen Miranda (MCM), Museu do I Reinado (MIR), Casa de Oliveira Vianna (COV), Museu dos Esportes (ME), Casa de Casimiro de Abreu (CCA) e Casa de Euclides da Cunha (CEC) - através de um navegador comum,(b) migrar os dados para um novo sistema de gerenciamento de coleções - o SISGAM - e (c) atualizar a base de dados de suas unidades disponibilizando-a através de um site institucional. Essas propostas visaram ampliar, através das facilidades da internet, o potencial cultural, artístico e educativo dos acervos dos museus, tornando os seus conteúdos informacionais acessíveis a um público mais amplo. Além disso, pretendeu otimizar o controle e a segurança das coleções dos museus.

Para os usuários - estudantes, pesquisadores e visitantes em geral - foi possível realizar pesquisas online através do acesso à base de dados dos museus, realizar visitas virtuais aos espaços, elaborar e executar projetos educativos utilizando recursos digitais oriundos das coleções dos museus, a partir dos conteúdos de qualidade disponíveis online.Para que tudo isso pudesse acontecer foi necessário que este material, a digitalização e a documentação dos acervos fossem tratados e organizados tecnicamente, potencializando os seus diversos usos culturais, educacionais e sociais.

Na primeira etapa do Projeto Rede de Museus,a equipe técnica da Diretoria de Museusestabeleceu as diretrizes para o desenvolvimento do projeto conceitual do sistema gerenciador da base de dados - Sistema de Gerenciamento de Acervos Museológicos (SISGAM) - e do portal dos museus, em conjunto com os consultores da empresa Infosys, os mesmos que haviam trabalhado no projeto de digitalização inicial, a qual foi designada no projeto para customizar a base tecnológica do banco de dados, implantar o programa, dar suporte às unidades museológicas para que o sistema de rede fosse instalado e desenvolver o site que abrigaria as páginas dos oito museus.

O primeiro grande desafio foi onde abrigar o portal e as informações das unidades. Por sermos uma instituição pública, optamos por realizar uma parceria 
com o PRODERJVI que abraçou o projeto e ofereceu toda a sua estrutura eprocedimentos de segurança tecnológica em apoio,além derealizar o projeto de infraestrutura elétrica e lógica para que as unidades pudessem receber o circuito INFOVIA, que interligaria os museus ao PRODERJ.

O Projeto consistia de um portal naweb que permitisse a pesquisa nos acervos dos museus integrantes da rede, acessíveis através de um navegador comum, por meio do link<www.museusdoestado.rj.gov.br>.

O SISGAM foi a ferramenta desenvolvida no projeto para interligar as unidades museológicas, utilizando normas e padrões que permitissem um melhor controle e gerenciamento de seus acervos. $\mathrm{O}$ software atendeu de forma completa às necessidades da documentação das coleções permitindo sua catalogação e gestão online, e ainda sua disponibilização na web.

As atividades de produção foram iniciadas em novembro do mesmo ano, quando foram liberados os recursos para o início dos trabalhos. A equipe contratada foi formada por 10 técnicos entre museólogos, bibliotecários, fotógrafo, conservadores e arquivista que receberam treinamento para realizar o processamento técnico do acervo obedecendo aos padrões estabelecidos pelo projeto.Foram ministradas oficinas para a equipe nas áreas de linguagem documentária, thesaurus e materiais e técnicas para acervos museológicos.

Oferecer informações padronizadas foi uma das principais iniciativas deste projeto, que, visando promover maior intercâmbio entre as bases de dados dos museus e facilitar a recuperação da informação de seus acervos, desenvolveu - Manual do Usuário do SISGAM, para ser utilizado pelos técnicos dos museus para a pesquisa e descrição dos recursos físicos dos itens de suas coleções proporcionando maior controle desses acervos.
Segundo Sayão (2016a), "Os metadados descrevem os atributos dos documentos [...] dando-lhes significado, contexto e organização, permitindo a produção, gestão, utilização deles ao longo do tempo.".

O manual visava atender as especificidades dos museus, que por serem de tipologia variada, necessitavam de procedimentos normatizados visando compatibilizar os campos existentes em suas planilhas de catalogação.

O tratamento do acervo museológico consistiu na conferência dos dados da ficha de cada objeto, assegurando a uniformidade das informações e a consistência técnica dos parâmetros estabelecidos. Após todas as informações terem sido conferidas, os acervos foram migrados para o novo sistema e, com a conclusão da última conferência, ficou constatado que não houve perdas de dados significativas nessa migração.

Em razão do grande número de peças das coleções dos museus e do tempo previsto para a realização do projeto, a equipe técnica de cada museu estabeleceu uma seleção prévia dos objetos cujas fichas seriam conferidas pelos técnicos contratados. Foram estabelecidos campos prioritários para a conferência e para a disponibilização de informações no acesso web. O critério de seleção foi definido a partir das peças e documentos que integrariam o futuro site e que fossem consideradas "high ligths" das coleções. Esse acervo, uma vez selecionado, foi todo fotografado e digitalizado. A seleção dos campos, para terem sua disponibilização na web, obedeceu a critérios de segurança estabelecidos pela equipe técnica dos museus.

Para se ajustarem aos layouts das páginas web e também para a incorporação no banco de dados, as imagens tiveram que passar por processos de edição e redimensionamento, que consistiu de ajustes na resolução espacial, na profundidade 
de cor e no formato de arquivo.Foram estabelecidas práticas baseadas em normas conhecidas e de uso amplo que orientaram todo o processo de edição de imagens.

O lançamento do Projeto Rede de Museus realizou-se dia 14 de maio de 2008, na sede do Instituto Oi Futuro, Rio de Janeiro, oficializando ao público o site desenvolvido com os recursos deste projeto, contendo as informações institucionais e dos acervos dos museus da estrutura administrativa da SEC-RJ/FUNARJ.

\section{A plataforma tecnológica da rede: o SISGAM}

O SistemaVII, que consiste em uma

[...] plataforma tecnológica online que in- terliga as instituições vinculadas à Rede Web de Museus para realizar a gestão e o registro dos seus acervos, utilizando normas e padrões que permitem um melhor gerenciamento e segurança dos mesmos (RIO DE JANEIRO, 2018),

foi o principal produto gerado pelo Projeto Rede de Museus. Através dele, os museus da FUNARJ puderamser acessados em um único portal na web, onde os acervos eram divulgados e consultados.

Abaixo, na figura 2, podemos observar a primeira interface do Sistema, onde eram reunidas imagens das fachadas dos museus estaduais, que, quando acessadas, forneciam informações principais a respeito de cada instituição, como horários de funcionamento, localização, breve históricoe contatos telefônicos.

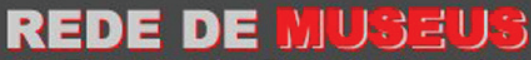

do Estado do Rio de Janeiro

Inicio Secretaria de Cultura Superintendência de Museus EUNARJ Museus Destaques Noticias Contato
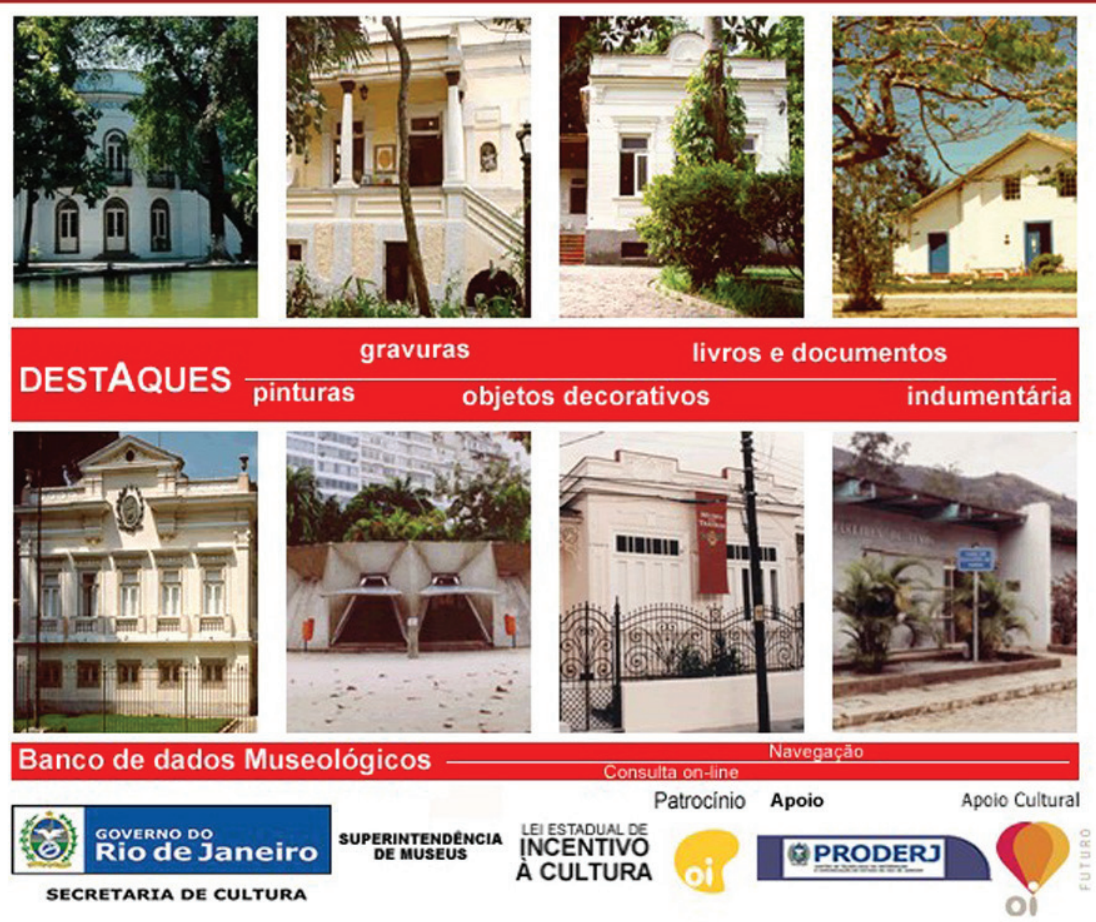

Figura 2 - Portal original do Projeto Rede de Musues

Fonte: RIO DE JANEIRO, 2011, slide 13 
Além da disponibilização online dos acervos da FUNARJ, o SISGAM promoveu maior dinamização nos procedimentos de documentação e catalogação dos bens, reforçando a segurança destas informações. $O$ Sistema realiza um controle eficaz do patrimônio museológico das instituições que o utilizam, envolvendo desde a entrada do objeto no museu, sua pesquisa, conservação, circulação e segurança até a sua disponibilização na web.O servidor do Sistema,ainda hoje, está hospedado no PRODERJ, con- tando com backups ${ }^{\mathrm{VIII}}$ diários dos dados e imagens registrados no SISGAM.

O acesso ao SISGAM pode ocorrer de duas maneiras, a primeira é a interface acessada pelo usuário web, uma interface apenas de busca por palavras ou números; a segunda é um acesso restrito, mediante e-mail e senha previamente cadastrados na Coordenação de Museologia da SMU. Podemos ver no quadro 1 abaixo o resumo dos níveis de acesso ao Sistema.

\begin{tabular}{|l|l|}
\hline \multicolumn{1}{|c|}{ Usuário } & \multicolumn{1}{c|}{ Permissões } \\
\hline Administrador & $\begin{array}{l}\text { Além de possuir todas as permissões dos demais perfis, gerencia as funções, } \\
\text { tabelas e os usuários de um museu; cadastra e desativa usuários no sistema. }\end{array}$ \\
\hline Catalogador & $\begin{array}{l}\text { Cadastra, atualiza ou edita as fichas catalográficas de cada item da } \\
\text { unidade, o catalogador também pode gerar relatórios técnicos dos acervos. }\end{array}$ \\
\hline Gerenciador de entrada & $\begin{array}{l}\text { Responsável por revisar as ações dos catalogadores e, além de } \\
\text { permissões semelhantes às do catalogador, pode liberar as fichas para } \\
\text { consulta on-line e gerar relatórios administrativos. }\end{array}$ \\
\hline Pesquisador interno & $\begin{array}{l}\text { Acessa o modo restrito e consulta todas as fichas catalogadas no sistema, } \\
\text { com restrição de campos de segurança e transações vinculadas às fichas. } \\
\text { Este usuário é comumente destinado a curadores de exposições e } \\
\text { produtoras, também pode ser atribuído a equipes de outras unidades que } \\
\text { precisem consultar integralmente a base de dados de um determinado } \\
\text { museu através de um cadastro e usuário com senha. }\end{array}$ \\
\hline Pesquisador weblexterno & $\begin{array}{l}\text { Usuário comum da web que pode consultar livremente o acervo liberado } \\
\text { para a pesquisa on-line. }\end{array}$ \\
\hline Restaurador & $\begin{array}{l}\text { Acesso destinado aos funcionários do Laboratório de Conservação } \\
\text { (LACON), este perfil é voltado para a inserção de dados somente na } \\
\text { transação "Conservação/Restauração" atividades desenvolvidas pelo } \\
\text { Laboratório, o perfil restringe ainda a visualização das transações de cada } \\
\text { peça para apenas o "Estado de Conservação" mais atual de cada item. }\end{array}$ \\
\hline
\end{tabular}

Quadro 1 - Perfis de acesso ao SISGAM

Fonte: SOUZA, 2018, p. 82

A interface voltada para o público externo consiste de um mecanismo de busca simples, onde podem ser feitas consultas ao catálogo de cada unidade cadastrada na rede e disponível para o usuário web, tendo em vista que a disponibilização para o público de um museu no SISGAM é gradativa, à medida que seu trabalho de inserção e revisão de dados e imagens de acervos é concluído. Os resultados podem ser exibidos apenas em imagens ou em imagens mais um resumo de sua ficha catalográfica. As figuras 3 e 4 permitem visualizar a apresentação da informação nas buscas de usuário web. 

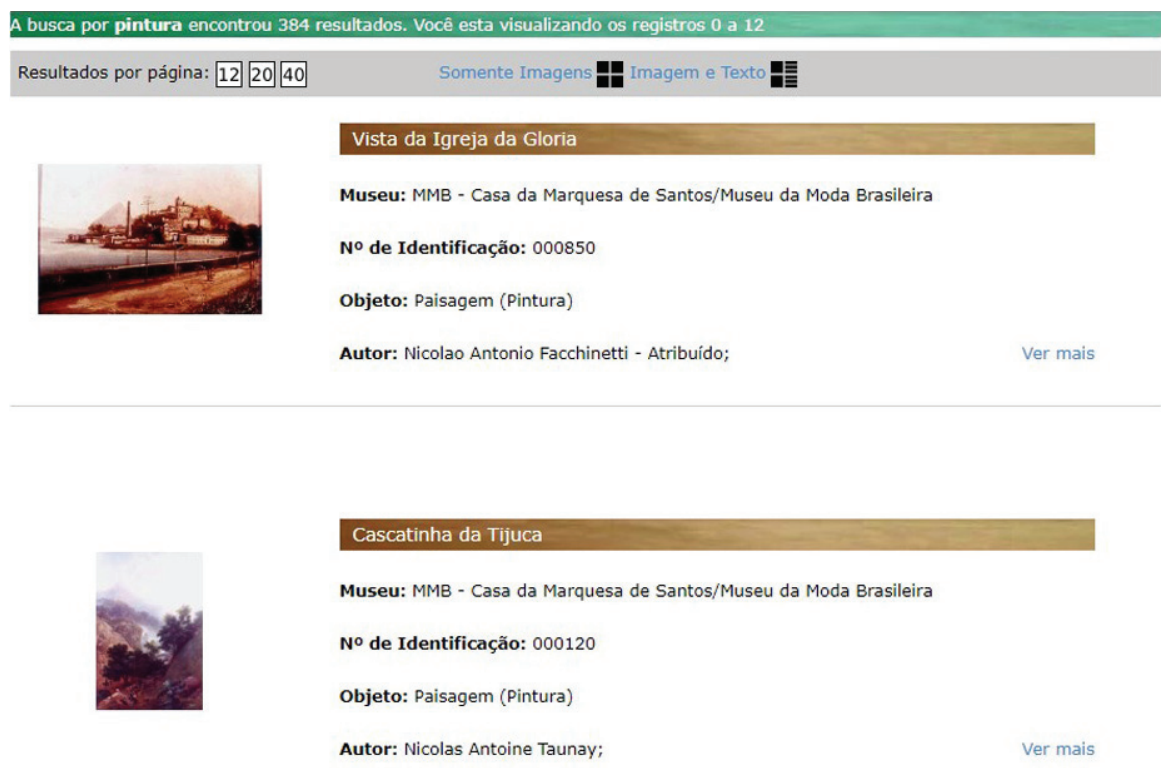

Figura 3 - Apresentação de busca para usuário web, interface de imagem e texto Fonte: Rede Web de Museus <http://www.museusdoestado.rj.gov.br/sisgam/index.php>
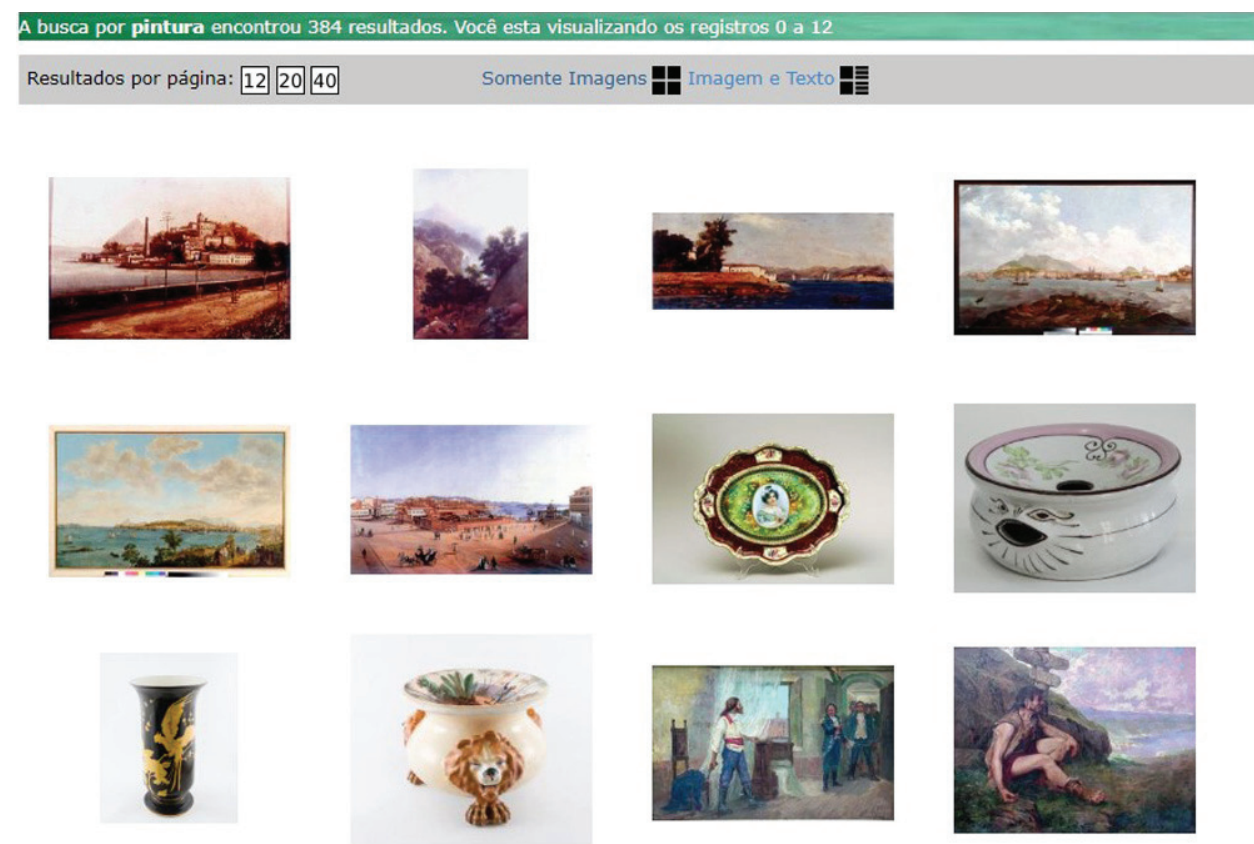

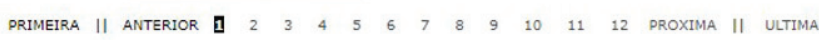

Figura 4 - Apresentação de busca para usuário web, interface somente imagens Fonte: Rede Web de Museus <http://www.museusdoestado.rj.gov.br/sisgam/index.php>

As informações e serviços voltados para o público interno consistem de funcionalidades através das quais é feita a gestão da base de dados do catálogo coletivo dos museus que integram a rede e só podem ser acessadas através de perfis com autorização para edição e consulta a estas áreas. É possível registrar informações pertinentes a transações e movimentações que envolvem os acervos, e as áreas são: estado de conservação, informando diagnóstico do objeto; avaliação monetária; ações de conservação e restaura- 
ção realizadas na peça; empréstimos externos e internos; participação em exposições; baixa de acervo e histórico de publicações.

A base possibilita ainda a geração de relatórios técnicos e administrativos com campos selecionados. Este recurso permite visualizar estatísticas técnicas e quantitativas do acervo e facilita também os procedimentos de controle de gestão e movimentação dos acervos, promovendo maior clareza e organização das informações em função do objetivo do relatório.

\section{Projeto Rede Web de Museus: integração e colaboração em rede}

Ambientes colaborativos são fundamentais para que as instituições culturais aumentem a eficiência na troca e no tratamento de seus dados. As ferramentas de colaboração contribuem para uma rápida evolução no tratamento e armazenamento das informações inseridas diariamente no ambiente digital, onde as instituições precisam oferecer respostas rápidas e eficientes no gerenciamento e disponibilização de seus acervos na web.

Em um cenário onde apenas os maiores museus estaduais têm seus acervos inventariados e digitalizados, e com base nos bons resultados obtidos com o trabalho que já vinha sendo realizado desde 2008 com os museus da SEC, a Superintendência de Museus delineou o Projeto Rede Web de Museus, que tinha como principal objetivo atender, no âmbito do estado do Rio de Janeiro, as instituições culturais que desejassem desenvolver um trabalho colaborativo, oferecendo orientação e ferramentas para a produção de acervos digitais e promovendo sua articulação em rede com outros equipamentos culturais. A consolidação da colaboração entre os integrantes do projeto- que organizam, inserem, disponibilizam e transmitem seus dados no SISGAM - ocorre na plataforma tecnológica em que os usuários trocam informações, experiências e intera- gem de forma contínua, usufruindo dos benefícios de um trabalho em rede.

Objetivando institucionalizar o projeto, a rede foi criada oficialmente em 21 de maio de 2014, através da Portaria $n^{\circ} 513$ da FUNARJ, onde seus objetivos e sua missão foram discriminados e que consistem em

[...] ampliar a disseminação dos acervos museológicos e a cooperação entre instituições nos campos do gerenciamento, documentação, pesquisa, educação, comunicação e integração dos acervos museológicos (BRASIL, 2014).

ARede Web de Museus oferece uma infraestrutura gerencial, tecnológica e de padronização que permite dinamizar a gestão cooperativa sobre os acervos dos museus vinculados à SEC-RJ e a outros que vierem a integrá-la, tendo em vista os avanços obtidos com a ampliação do acesso, a oferta de serviços integrados e a presença na web, alcançados pelo projeto inicial, em 2007/2008.Para isso dispôs de um conjunto de instrumentos normativos, metodológicos, tecnológicos e gerenciais e de portal unificado de consulta pública para disponibilizar aos seus colaboradores, de modo que o SISGAM, cuja eficiência na recuperação da informação e gestão dos acervos do estado vinha sendo comprovada desde sua implementação, foi oferecido às instituições que formalizassem suas adesões.

Primeiramente foram convidadas a aderir à Rede as instituições culturais que haviam sido contempladas em editais fomentados pela SEC-RJ, estabelecendo-se um critério inicial com o objetivo de estreitar as relações de cooperação entre estas instituições e a Superintendência de Museus. Posteriormente, com a colaboração do Sistema de Museus do Estado do Rio de Janeiro (SIM$-\mathrm{RJ}$ ), as adesões à Rede passaram a ser divulgadas através de seus canais de comunicação e várias solicitações de adesões foram recebidas pelos gerenciadores do projeto. 
A adesão à Rede Web de Museus pode ser feita de duas formas: colaborativa e plena. A adesão colaborativa destina-se às instituições que possuem um sistema próprio de documentação, mas que passam a integrar de forma colaborativa a Rede Web de Museus, disponibilizando informações, através de alguns campos básicos de catalogação e imagens de parte do seu acervo. A adesão plena destina-se às instituições que não possuem um sistema próprio de documentação e gerenciamento de acervo, que passam a integrar de forma plena a Rede Web de Museus, como usuária do SISGAM, recebendo da Rede assistência técnica e metodológica e tendo a possibilidade de cadastrar um conjunto de usuários-senhas do SISGAM que the permita trabalhar regularmente na catalogação de seus acervos.

Independente da forma de adesão, além de participação da Rede, a pesquisa transversal nas coleções é estimulada através do SISGAM de forma a proporcionar novas curadorias e geração de conhecimento.

No intuito de viabilizar a exportação de dados gerados no ambiente da rede, o SISGAM possui em seu elenco os principais campos para descrição de acervos museológicos, sendo capaz de realizar a exportação destes dados em formatos como XML, Excel e Dublin Core.

Atualmente fazem parte da Rede 27 instituições culturais, de diversas esferas administrativas, sendo que 4 aderiram de forma plena e 15 de forma colaborativa, as demais pertencem à SEC-RJ, algumas cedidas às Prefeituras das suas respectivas cidades. Ao todo, o SISGAM possui em sua estrutura 96.355 fichas catalográficas, das quais, cerca de $70 \%$ provêm dos museus que aderiram à Rede.

Durante o desenvolvimento do projeto, verificamos que as principais dificuldades de operacionalização das atividades estavam relacionadas à disponibilização de recursos humanos dos museus para realização do tra- balho. Em alguns casos, foi necessário que a própria equipe da Coordenação de Museologia auxiliasse na inserção de dados. Também entraves relacionados a direitos autorais dificultam um pouco o nosso trabalho.

Futuros desdobramentos para o projeto estão sendo idealizados, como a atualização do SISGAM, trazendo novas funcionalidades de gerenciamento e pesquisa para os usuários do sistema, oferecendo facilidades para a elaboração, por parte de curadores ou professores, de exposições ou aulas virtuais com comentários ou textos agregados, enriquecendo o potencial educativo e potencializando as sinergias existentes entre os acervos das diferentes instituições da Rede.

Pretende-se também oferecer a opção de "navegação" pelas categorias do Thesaurus facilitando a recuperação de registros de peças museológicas disponíveis em diferentes instituições. Maior integração com as redes sociais também está sendo viabilizada.

A intenção é a de que a Rede Web de Museus possa ter mecanismos de fóruns próprios de gestão e sustentabilidade. Assim a Rede ampliará suas oportunidades de se desenvolver, de desenvolver projetos colaborativos e de obter mais fomento para os museus do estado. Estão previstos futuros desenvolvimentos na plataforma SISGAM para facilitar a sua utilização pelas instituições que fazem parte da Rede.

\section{Considerações finais}

Democratizar o acesso a coleções públicas na web, oferecendo informações culturais de qualidade, faz com que estes acervos sejam vistos por um público muito maior, que tem a possibilidade de se apropriar de seus conteúdos para utilizar em diversas atividades, proporcionando assim uma circulação desses acervos que o museu físico não conseguiria realizar. Ao mesmo tempo, ir ao museu, apreciar as coleções e participar de suas 
atividades, é uma experiência sensorial que não pode ser obtida através do computador.

As políticas públicas devem não só fomentar a digitalização dos acervos públicos e sua disponibilização na rede, mas prover sustentabilidade para os projetos que atendam a estes objetivos. Devem também enfatizar o acesso qualificado, promovendo a interação do público com essas obras em formatos digitais, criando novas conexões com outros objetos e fatos, gerando assim novos conteúdos e outras formas de conhecimento.

Pudemos perceber com o Projeto Rede Web de Museus, em um contexto estadual, que os programas de digitalização de acervos se encontravam desintegrados, ou seja, cada instituição trabalha pensando em resolver os seus próprios dilemas, utilizando o seu próprio software, metodologia e padrões, muitas vezes por falta de opção e recursos,sem mesmo ter conhecimento dos bons resultados que um trabalho integrado pode trazer. A proposta da Rede Web reforça a ideia de um trabalho em rede, gerido por normas e padrões específicos e que possa integrar diferentes instituições, sejam elas de grande ou pequeno porte, possibilitando o intercâmbio de informações e experiências entre elas, facilitando a disponibilização e a disseminação de seus acervos na rede.

Segundo Machado, Sayão e Marcondes (2014), a política e o fomento implícitos na proposta da Rede Web de Museus partem do pressuposto de que com seus próprios recursos, a presença de um museu na web envolve tecnologia, expertise e custos bastante significativos. Ao fomentar estes recursos e torná-los disponíveis aos museus do estado, a Rede se constitui num instrumento político para fomentar a ampliação do acesso, a oferta de serviços integrados e a presença na web desses acervos.

Acreditamos que o fomento e a sustentabilidade a projetos que enfoquem aintegração, organização e acesso aos conteúdos digitalizados pelas instituições públicas ou privadas, assim como a demais conteúdos disponibilizados na rede por entidades ligadasà cultura, possam trazer maior integração entre os setores que atuam na área, dando maior ênfase à preservação da memória e à democratização do acesso aos acervos digitais.

\section{Referências}

ABBOTT, Daisy. What is digital curation? In: ABBOTT, Daisy. DCC Briefing Papers: introduction to curation. Edimburgo: Digital Curation Centre, 2008. Disponível em: <http://www.dcc.ac.uk/resources/ briefing-papers/introduction-curation/what-digital-curation>. Acesso em: 12 dez. 2018.

BRASIL. Fundação Anita Mantuano de Artes do Estado do Rio de Janeiro - FUNARJ. Portaria $n^{\circ} 513$, de 21 de maio de 2014. Dispõe sobre instituição da Rede Web de Museus do Estado do Rio de Janeiro, no âmbito da Fundação Anita Mantuano de Artes do Estado do Rio de Janeiro - FUNARJ. Diário Oficial do Estado do Rio de Janeiro, RJ, 23 maio 2014. Parte 1, p. 47. Disponível em: <https://www.jusbrasil.com.br/diarios/70995850/doerj-poderexecutivo-23-05-2014-pg-47>. Acesso em: 02 dez. 2017.

Digital Curation Centre - DCC. The DCC Curation Lifecycle Model. Edimburgo: Universidade de Edimburgo, 2014b. Disponível em: <http://www. dcc.ac.uk/sites/default/files/documents/publications/DCCLifecycle.pdf>. Acesso em: 18 fev. 2018.

Digital Curation Centre - DCC. What is Digital Curation? Edimburgo: Universidade de Edimburgo, 2014a. Disponível em: <http://www.dcc.ac.uk/digital-curation/ what-digital-curation>. Acesso em: 25 nov. 2016.

Digital Preservation Coalition - DPC. Preservation management of digital materials: the handbook. Glasgow: Universidade de Glasgow, 2008. Disponível em: <http://www.dpconline.org/docman/ digital-preservation-handbook/299-digital-preservation-handbook/file>. Acesso em: 02 dez. 2018.

LÉVY, Pierre. A cibercultura. In: SCHEINER, Thereza (Org.). Museologia 1: bases teóricas da museologia. Rio de Janeiro: Universidade Federal do Estado do Rio de Janeiro, Escola de Museologia, 2009. p. 76-82. Apostila. 
MACHADO, Elenora; SAYÃO, Luis Fernando, MARCONDES, Carlos Henrique. "Navegando" entre acervos Museológicos do Estado do Rio de Janeiro. In: SEMINÁRIO BRASILEIRO DE MUSEOLOGIA. Belo Horizonte. Nov. 2014. Anais... Disponível em: <https://anaissebramus.files.wordpress.com/2015/06/ anais-completo.pdf>. Acesso em: 02 dez. 2018.

MARTINS, Dalton Lopes; SILVA, Marcel Ferrante; CARMO, Danielle do. Acervos em rede: perspectivas para as instituições culturais em tempos de cultura digital. Em questão, Porto Alegre, v. 24, n. 1, jan./ abr., 2018. Disponível em: <http://www.seer.ufrgs. br/index.php/EmQuestao/article/view/72951/44342>. Acesso em: 02 dez. 2018.

RIO DE JANEIRO (Estado). Secretaria de Cultura. Superintendência de Museus. SISGAM - Acervo na Web. Rio de Janeiro: SMU/SEC-RJ, 2018. Disponível em: <http://www.museusdoestado.rj.gov.br/acervoweb/>. Acesso em: 02 dez. 2018.

RIO DE JANEIRO (Estado). Secretaria de Cultura. Superintendência de Museus. SISGAM: Sistema de Gerenciamento de Acervos Museológicos. Rio de Janeiro, 2011. 30 slides. Apresentação em PowerPoint.

SANTOS, Thayse Natália Cantanhede. Curadoria digital: o conceito no período de 2000 a 2013. Brasília, 2014, 116 f. Dissertação (Mestrado em Ciência da Informação) - Faculdade de Ciência da Informação, Universidade de Brasília. Disponível em: <http://repositorio. unb.br/bitstream/10482/17324/1/2014_ThayseNataliaCantanhedeSantos.pdf>. Acesso em: 02 dez. 2018.

SAYÃO, Luis Fernando. Aula de preservação digital ministrada na Fundação Casa de Rui Barbosa. Rio de Janeiro, 2016a, 96 slides. Apresentação em PowerPoint.

SAYÃO, Luis Fernando. Digitalização de acervos culturais: reuso, curadoria e preservação. In: SEMINÁRIO DE SERVIÇOS DE INFORMAÇÃO EM MUSEUS: informação digital como patrimônio cultural, 4., 2016, São Paulo. Anais... São Paulo: 2016b.

SCHEINER, Thereza. Museu, ecomuseu, anti-museu. In: SCHEINER, Thereza (Org.). Museologia 1: bases teóricas da museologia. Rio de Janeiro: Universidade Federal do Estado do Rio de Janeiro, Escola de Museologia, 2009. p. 50-57. Apostila.

SOUZA, Éricka Madeira de. A curadoria digital e o reuso dos acervos culturais digitais da Rede Web de Museus do Estado do Rio de Janeiro. 2018, 125 f. Dissertação (Mestrado Profissional em Memória e Acervos) - Programa de Pós-Graduação em Me- mória e Acervos, Fundação Casa de Rui Barbosa, Rio de Janeiro, 2018.

VARINE, Hughes de. Repensando o conceito de museu. In: SCHEINER, Thereza (Org.). Museologia 1: bases teóricas da museologia. Rio de Janeiro: Universidade Federal do Estado do Rio de Janeiro, Escola de Museologia, 2009. p.31-35. Apostila.

\section{Recebido em 18/12/2018 Aprovado em 24/01/2019}

I Elenora Nobre Machado. Museóloga, Casa da Marquesa de Santos / FUNARJ /Secretaria de Estado de Cultura RJ. Rio de Janeiro, Brasil. Contato: elenora.cultura@gmail.com

II Éricka Madeira de Souza. Mestre em Memória e Acervos, Superintendência de Museus / Secretaria de Estado de Cultura RJ. Rio de Janeiro, Brasil. Contato: emsouza. cultura@gmail.com

III International Council of Museums (Conselho Internacional de Museus), ver <https://icom.museum/en/>.

IV "[...] actions required to maintain access to digital materials beyond the limits of media failure or technological change." [tradução nossa].

V Centro de expertise em Curadoria Digital, existente desde 2004, oriundo de uma cooperação entre a Universidade de Edimburgo e a Universidade de Glasgow, ambas do Reino Unido.

VI PRODERJ, Centro de Tecnologia da Informação e Comunicação do Estado do Rio de Janeiro, http://www. proderj.rj.gov.br/.

VII O Sistema pode ser acessado através do link: <http://www.museusdoestado.rj.gov.br/acervoweb/>.

VIII Na área da informática, backup é uma cópia de segurança dos dados digitais.

IX O LACON é subordinado à Superintendência de Museus e atende às demandas de todas as unidades vinculadas à FUNARJ e à SMU, mas é sediado no Museu do Ingá, em Niterói. 